\title{
Bioassay of Herbal Mosquito Repellent Formulated from the Essential Oil of Ocimum Basilicum
}

\author{
Amar Osman Ali Salih ${ }^{1, *}$, Missa Mohammed Saleh, Mahmoud Mohamed Ali \\ ${ }^{1}$ Ministry of Higher Education and Scientific Research, Chemistry Department, Central Lab, Khartoum, Sudan \\ ${ }^{2}$ Department of Chemistry, International University of Africa, Khartoum, Sudan
}

Email address:

osmanamar607@gmail.com(A. O. A. Salih)

*Corresponding author

\section{To cite this article:}

Amar Osman Ali Salih, Missa Mohammed Salih, Mahmoud Mohamed Ali. Bioassay of Herbal Mosquito Repellent Formulated from the Essential Oil of Ocimum Basilicum. American Journal of Applied Chemistry. Vol. 6, No. 4, 2018, pp. 132-141. doi: 10.11648/j.ajac.20180604.11

Received: March 3, 2018; Accepted: April 2, 2018; Published: August 17, 2018

\begin{abstract}
The plants are one of the most important drugs of sources. For example, (sweet basil) is one of these plant tribes that symbolize all that is extraordinary in nature, because the entire plant has been used by traditional medicine for the treatment of the family against various human diseases of antiquity. The aim of this paper is to review the literature on basil; samples were collected from different farms of Khartoum state, specifically the oil that is extracted by cold extraction with water and effectiveness against bacteria and toxicity and effectiveness against oxidative stress and therapeutic benefits studied scientifically. This review consists of all relevant basil that has been identified by researchers through the systematic research of major medical computerized data base publications. Our Study indicate that own basil analgesic, anti-inflammatory, antimicrobial, antioxidant, and the activities of the larvae, uses in medicine Traditional and tonic and repellent mosquito and in this research were prepared cream repellent mosquito formula and proven experience success and effectiveness of this very great benefit if it reduces the incidence of malaria and protect against mosquito bites people. These results are very encouraging and indicate that this cream should be taught more widely to confirm these results and to find other Potential therapeutic effects were achieved the goals set in the research.
\end{abstract}

Keywords: Sweet Basil, Mosquito, Repellent, Ocimum Basilicum, Therapeutic

\section{Introduction}

Mosquitoes are among the most disturbing blood sucking insects afflicting human beings [1]. The behavior of female mosquitoes involving feeding on human blood is responsible for the transmission of a number of diseases. The most prevalent ones being malaria, bancroftianfilariasis, yellow fever, dengue fever and several arbovirus infections, it is a matter of fact that the transmission of these infections to humans totally depends upon the availability of competent mosquito vectors; hence, mosquito control initiatives remain the most successful mechanism for disease prevention and control ${ }^{1}$.Among the efforts that have been made in recent decades in seeking to reduce mosquito bite and malaria transmission is the introduction and use of insecticides treated nets (ITNs), especially with pyrethroids, to enhance the protective utility of the nets. Since, unlike ITNs, untreated nets do not repel or kill mosquitoes, they allow mosquitoes to bite through them, or if the net is torn, to enter through a hole. Mosquitoes can bite people before retiring to bed or wait and bite when people get out of the net at night. The mosquito repellent products commonly available on the market contain N, N-diethyl- 3-toluamide (DEET) as the active ingredient. DEET is a wide-spectrum repellent that is effective against mosquitoes and other biting insects. However, DEET has operational disadvantages due to its allergic actions and toxicity to man, such our study to repellent of mosquito by Ocimum basilicum oil. Earlier hopes of malaria eradication by getting rid of mosquito vectors had only limited success due to the development of insecticide resistance by mosquitoes. However, the major jolt to human fight against malaria has come from emergence of drug resistant strains of Plasmodia. A viable alternative strategy 
for controlling mosquito-borne diseases would involve the assessment of plant compounds or extracts as natural repellents or insecticides which will counteract the effect of rapid development of insecticide resistance to the available synthetic insecticides including pyrethroids. Scientific investigations has for long appreciated that, co-evolution has equipped plants with a variety of chemical defenses against insect predators. While aware of this effect, mankind has used plant parts or extracts to control insects since ancient times. Plant derived products have received increased attention from scientists and more than 2000 plant species are already known to have insecticidal properties [2] .

\section{Materials and Methods.}

\subsection{Source of Leaves}

The leaves of ocimumbasilcum plant were obtaining in septum 2014 from farmer in Khartoum state (soba-sham bat).The leave was first washed and shade dried. The pulp and stone were separated. Were shade dried and powdered to be used in further analysis.

\subsection{Chemicals and Reagents}

Chemicals and reagents used in this study were of analytical grade.

\subsection{Methods}

\subsubsection{Steam Distillation Extraction}

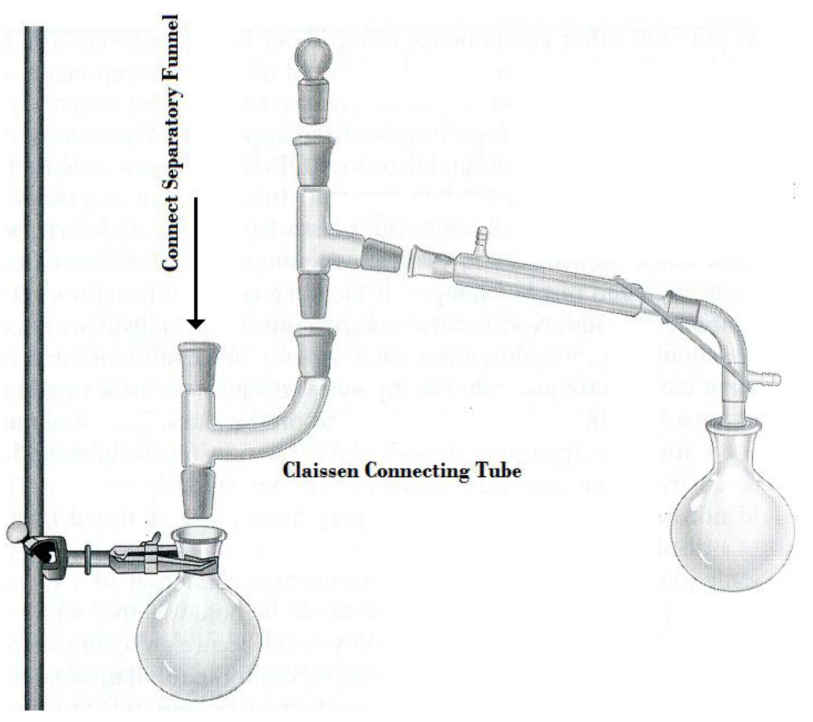

Figure 1. Diagram of steam distillation.

In this laboratory exercise we will employ Steam Distillation to isolate an Essential Oil from part of leaves. This will involve distilling a mix of the plant material and Water to obtain the Oil, extracting the Oil from the Water, and then isolating the Oil from the extraction solvent. In the end, we will analyze the Oil's composition by separating its constituents using Gas Chromatography. Essential Oils are a mix of fragrant compounds common to a number of plants such as basil, Lavender, Pine, etc. which are isolated via steam distillation. Because these Oils were once considered to be the essence of the plant, they were initially sought as possible pharmaceuticals and are a part of early medicine's contribution to modern chemistry. Today they are used as flavorings, perfumes and deodorants. Essential Oils are mixtures of organic compounds that are dominated by the Terpenes and the Terpenoids, oxygen containing derivatives of the terpenes. Terpenes themselves are a class of compounds built on the five carbon skeletal fragment of Isoprene [3].

\subsubsection{Oil Extraction and Determination of Oil Content}

The oil content of the sample was determined according to using Soxhlet apparatus as follows:

40 grams of sample were taken and placed in a thimble. The thimble was covered using cotton wool. An empty, dry and clean round flask with a known weight was connected to siphoning apparatus and $200 \mathrm{ml}$ water (with a boiling point of 50 to $60^{\circ} \mathrm{C}$ ) were added. Extraction was carried out for 4 $\mathrm{hr}$ during which the solvent was distilled off. The round flask containing the extracted fat was weighted[ 4].The extracted oil was calculated and expressed as percentage according to the equation:

$$
\text { Oil content } \%=\frac{\left(W_{2}-W_{1}\right) \times 100}{S}
$$

Where:

$\mathrm{W}_{1}$ : Weight of empty round flask

$\mathrm{W}_{2}$ : Weight of the round flask containing the extracted fat

$\mathrm{S}$ : Original weight of the sample

The oil obtained was thereafter stored up in hermetically closed bottles and kept in a refrigerator till further analysis.

\subsection{Determination of Antimicrobial Activity}

\subsubsection{Culture Media}

Culture medium or growth medium is a liquid or gel designed to support the growth of microorganisms. There are different types of media suitable for growing different types of cells.

\subsubsection{Nutrient Broth}

This medium contained peptone, yeast extract and sodium chloride. It was prepared by dissolving13 grams of the medium in one liter of distilled water. The $\mathrm{pH}$ of the medium was adjusted to 7.4 and the medium was then distributed into screw capped bottles, $5 \mathrm{ml}$ each and sterilized by autoclaving at $121^{\circ} \mathrm{C}$ for 15 minutes [5].

\subsubsection{Nutrient Agar}

The medium contained lab- lemco powder (1.0 g) yeast extract $(2.0 \mathrm{~g})$, peptone $(5.0 \mathrm{~g})$ and agar No.3 (15.0 g). Twenty eight grams of dehydrated medium were dissolved in one liter of distilled water and the $\mathrm{pH}$ was adjustedto7.4. The dissolved medium was sterilized by autoclaving at $121^{\circ} \mathrm{C}$ for 15 minutes. 


\subsubsection{Mueller Hinton Agar}

Mueller Hinton dehydrated media (38g) was dissolved in $1000 \mathrm{ml}$ of purified filtered water and heated with frequent agitation. Media was sterilized at $121^{\circ} \mathrm{C}$ for 15 minutes and cooled to $45-50^{\circ} \mathrm{C}$ and dispensed into sterile Petri dishes.

\subsubsection{Preparation of Reference Strains of Bacteria}

One $\mathrm{ml}$ aliquotsof $24 \mathrm{~h}$ broth culture of tested organisms was aseptically added to nutrient agar slopes and incubated (Griffin and George Ltd, England) at $37^{\circ} \mathrm{Cfor} 24 \mathrm{~h}$. The bacterial growth was harvested and was hed off by addition sterile normal saline. The harvested bacteria were suspended in suitable volume of normal saline to produce suspension containing bout $10^{8}-10^{9}$ colonyformingunitsperml (cfulml). The suspension was stored in the refrigerator at $4^{\circ} \mathrm{C}$ till used. The average number of viable organisms per $\mathrm{ml}$ of the stock suspension was determined by means of the surface viable counting technique [6].

\subsubsection{Testing for Antibacterial Activity}

The antimicrobial activity test was performed using the disc diffusion assay ${ }^{7}$.Sterile filter paper discs (Whatman No.1, $0.5 \mathrm{~mm}$ in diameter) were impregnated with one $\mathrm{ml}$ of each extract $(20 \mathrm{mg} / \mathrm{ml})$ and left to dry so as to remove residual solvent, which might interfere with the determination. A bacterial suspension was prepared and added to the sterilized medium before solidification. The media with bacteria was poured into sterilized Petri dishes under aseptic condition. Extract discs were then placed on the seeded agar plates. Each extract was tested in triplicate. Muller Hinton Agar plates were inoculated with $0.2 \mathrm{ml}$ bacterial suspension of overnight culture of each bacterium and uniformly spread out. Duplicates were maintained. The plates were incubated at room temperature for 24 hours. After the incubation period, the inhibition zone was around the discs were measured and recorded, each test was carried out in triplicates [7].

\subsection{Determination of Antioxidant Activities of Basil Oil}

The DPPH radical scavenging was determination with some Modification. In96-wells plate, the test sample were allowed to react with 2.2Di (4-tert-octylphenyl)-1-picrylhydrazyl stable free radical (DPPH) for half an hour at $37 \mathrm{c}$. The concentration of DPPH was kept as (300Um). The test sample was dissolved in DMSO while DPPH was prepared in ethanol. After incubation, decrease in absorbance was measured at $517 \mathrm{~nm}$ using multiplate reader spectrophotometer. Percentage radical scavenging activity by sample was determined in comparison with a DMSO treated control group. All tests and analysis were run in triplicate [8].

\section{6. $I C_{50}$ Calculation}

The $\mathrm{IC}_{50}$ (the concentration of test, material, which possess $50 \%$ inhibition of free radicals) of all the extracts and their fractions was determined by monitoring the effect of different concentrations ranging from $500-62.25 \mu \mathrm{g} / \mathrm{ml}$. the
$\mathrm{IC}_{50}$ of the extracts and their fractions were calculated using EZ-FIT Enzyme kinetic program (Perrella scientific, U.S.A).

\subsection{Cytotoxicity}

\subsubsection{Brine Shrimp Lethality Test}

Several studies had shown that brine shrimp lethality is a general bioassay which is an excellent method for preliminary investigations of toxicity in order to screen medicinal plants popularly used for several purposes and for monitoring the isolation of biologically active compounds ${ }^{10}$. The technique is easily mastered, costs little and utilizes small amount of the test material. The brine shrimp assay has been successively employed for bioassay-guided fractionation of active cytotoxicity and antitumor agents they also reported that there is a positive correlation between the lethality to brine shrimp and the corresponding lethal oral dose in mice [9].

\subsubsection{Product Identification and Description (A. Salina)}

Artemia cysts, batch number DE RP 33801 was purchased from JBL Gmbh \& Co.KG (Neuhofen Germany) and the product was labeled as JBL Artemiopur Brand. The Artemia cysts had been harvested from Great Salt lake,Utah, USA and were identified as $A$. salina, based on zo-ogeography. $A$. salinais the best studied of the Artemia species, estimated to represent over $90 \%$ of studies in which Artemia is used as an experimental test organism.

\subsubsection{Culture and Harvesting of A. salina}

A. salinacysts were stored at $-20^{\circ} \mathrm{C}$ before use. $A$. salinacysts were incubated for hatching in a shallow rectangular dish $(14 \mathrm{~cm} \times 9 \mathrm{~cm} \times 5 \mathrm{~cm})$ filled with $225 \mathrm{ml}$ of a $3.3 \%$ solution of artificial sea water. A plastic divider with several $2 \mathrm{~mm}$ holes was clamped in the dish to make two unequal compartments. The cysts (1.11 grams) and yeast (0.0827 grams) were sprinkled into the larger compartment which was darkened. The smaller compartment was illuminated by a tungsten filament light and gently sparged with air. After 24 hours, hatched A. salina cysts were transferred to fresh artificial sea water and incubated for a further 24 hours under artificial light with air sparging. The phototropic nauplii were collected by pipette from the lighter side having been separated by the divider from the shells.

\subsubsection{Preparation of Test Extract}

The extract dissolved in dimethyl sulphoxide (DMSO). Test extracts at approparite amounts $(5 \mathrm{ml}, 50 \mathrm{ml}$, and $500 \mathrm{ml}$ for $10 \mathrm{ppm}, 100 \mathrm{ppm}$ and $1000 \mathrm{ppm}$ respectively) were transferred into vials ( 9 vials for each dose and 1 for control). Three replicates were prepared for each dose level. The following extracts were used for the bioassay: oil basilicumocimum.

\subsubsection{Bioassay}

Ten shrimps were transferred to each sample vial using disposable pipette, and artificial sea water was added to make $5 \mathrm{ml}$. Vials were left for 24 hours and numbers of survived larvae were counted. Data were analyzed by Finney Probit Analysis computer program to determine LD50 values with 
$95 \%$ confidence intervals [10].

\section{Result and Discussion}

\subsection{Anti-bacterial Activity}

The antibacterial activity of three concentration extracts from leaves of $O$. basilicum was determined against the Gram negative Escherichia coli and Pseudomonas aeruginosa and the Gram positive Salmonella typhi andStaphylococccus aureususing the disc diffusion method. Results are presented in Table 1 and plates $4 \& 5$.

Table 1. Showed antimicrobial activity of the ocimumbasilicum oil and standard antibiotics.

\begin{tabular}{|c|c|c|c|c|}
\hline Concentration & Pseudomonas aeruginosa & Staphylococcus aureus & Salmonellatyphi & Escherichiacoli \\
\hline $20 \mathrm{mg} / \mathrm{ml}$ & $25 \mathrm{~mm}$ & $19 \mathrm{~mm}$ & $18 \mathrm{~mm}$ & $24 \mathrm{~mm}$ \\
\hline $10 \mathrm{mg} / \mathrm{ml}$ & $19 \mathrm{~mm}$ & $18 \mathrm{~mm}$ & $16 \mathrm{~mm}$ & $20 \mathrm{~mm}$ \\
\hline $5 \mathrm{mg} / \mathrm{ml}$ & $13 \mathrm{~mm}$ & $15 \mathrm{~mm}$ & $14 \mathrm{~mm}$ & $12 \mathrm{~mm}$ \\
\hline Ampicillin(20 mcg/disc) & - & $11 \mathrm{~mm}$ & $20 \mathrm{~mm}$ & $20 \mathrm{~mm}$ \\
\hline Ciprofloxacin $(5 \mathrm{mcg} /$ disc & $35 \mathrm{~mm}$ & $10 \mathrm{~mm}$ & $20 \mathrm{~mm}$ & $33 \mathrm{~mm}$ \\
\hline Gintamicin(10mcg/disc) & $8 \mathrm{~mm}$ & $17 \mathrm{~mm}$ & $25 \mathrm{~mm}$ & $17 \mathrm{~mm}$ \\
\hline
\end{tabular}
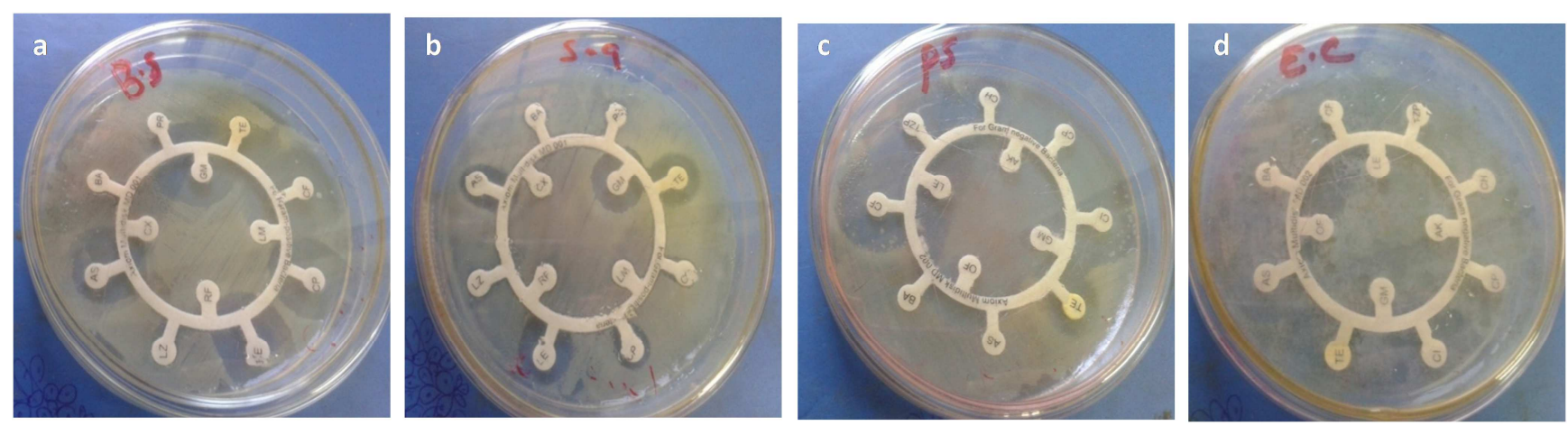

Figure 2. Antibacterial activity of standard antibiotic; ampicillin (20 mcg/disc), ciprofloxacin (5 mcg/disc) and gintamicin (10 mcg/disc) a, against Salmonella typhi; b, against Staphyllococcus aureus; c, against Pseudomonas aeruginosa \& d, against Escherichia coli.

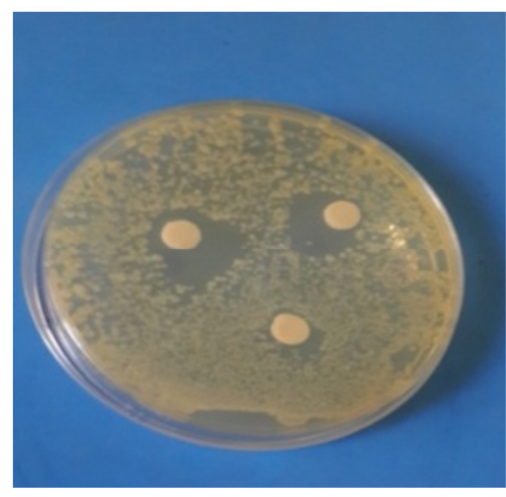

Figure 3. S.A.

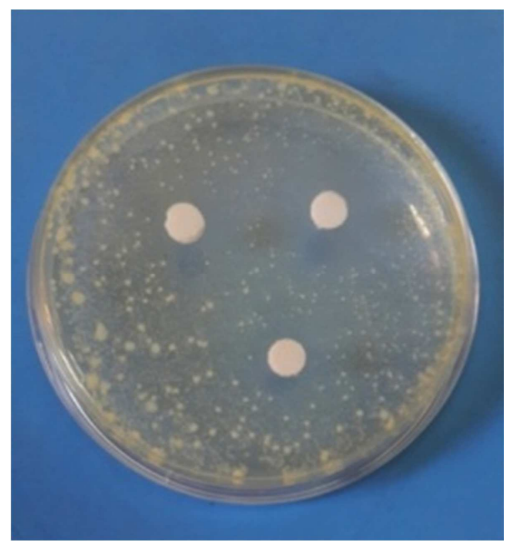

Figure 4. sa t.

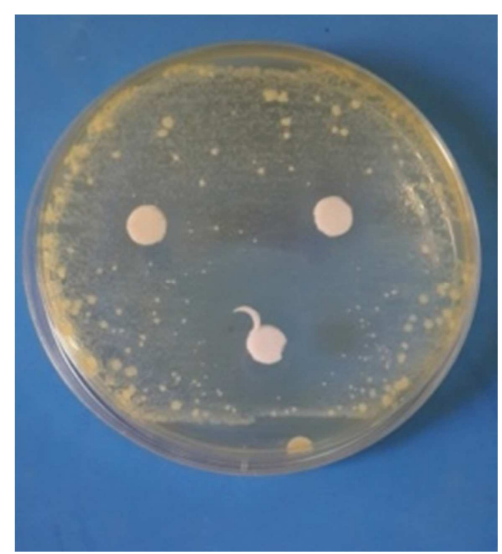

Figure 5. E.C.

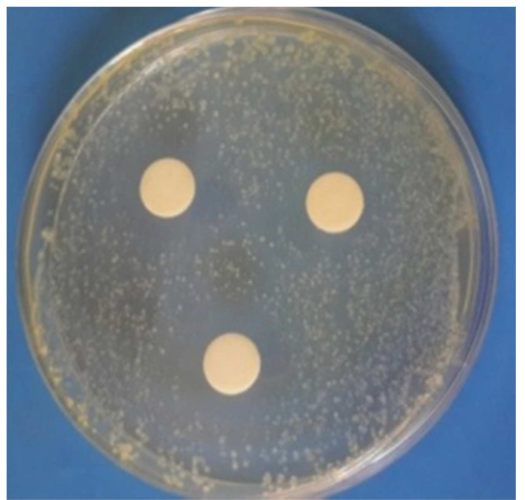

Figure 6. p.s. 
Figure 3, 4, 5, 6: Antibacterial activity of ocimumbasilicum, against Staphylococcus aurous, Salmonellatyphi and Escherichia coli, Pseudomonas aeruginosa.

\subsection{Antibacterial Activity of Extracts Against Test Organisms}

The result are shown in table (1) clearthe result exhibited by $O$. basilcum extracts $(20 \mathrm{mg} / \mathrm{ml}, 10 \mathrm{mg} / \mathrm{ml}$ and $5 \mathrm{mg} / \mathrm{ml}$ ) against Escherichia colishowedinhibition zone ( $12 \mathrm{~mm}, 24$ $\mathrm{mm}$ and $20 \mathrm{~mm}$ ) The highest activity $(24 \mathrm{~mm})$ was obtained from the second concentration. The highest activity showed by (and $20 \mathrm{mg} / \mathrm{ml}, 10 \mathrm{mg} / \mathrm{ml}$ and $5 \mathrm{mg} / \mathrm{ml}$ ) against $P$. aeruginosa $(25 \mathrm{~mm})$ followed by $(19 \mathrm{~mm}$ and $13 \mathrm{~mm})$. All extracts were susceptible against Salmonella typhi with inhibition zones $(18 \mathrm{~mm}, 16 \mathrm{~mm}$ and $14 \mathrm{~mm})$. The result of the extracts $(20 \mathrm{mg} / \mathrm{ml}, 10 \mathrm{mg} / \mathrm{ml}$ and $5 \mathrm{mg} / \mathrm{ml})$ against $S$. aurous (19mm, $18 \mathrm{~mm}$ and $15 \mathrm{~mm}$ ).

\subsection{Anti-oxidant Activity}

Table 2. Showed Antioxidant activity of ocimumbasilicum oil.

\begin{tabular}{ll}
\hline Sample name & RSA\% \pm SD \\
\hline Basil oil & $73 \pm 0.15$ \\
Propyl galate(PG) & $85 \pm 0.01$ \\
\hline
\end{tabular}

Table 3. IC $C_{50}$ value of extracts of ocimumbasilicum.

\begin{tabular}{lll}
\hline No & SampleIC $_{\mathbf{5 0}}$ & IC $_{\mathbf{5 0}} \pm$ SDmg/ml(DPPH) \\
\hline 1 & Ocimumbasilicum oil & $0.101 \pm 003$ \\
2 & PG & $0.044 \pm 0.011$ \\
\hline
\end{tabular}

\subsubsection{DPPH Free Radical Scavenging Activity}

DPPH free radical scavenging activity the stable radical DPPH has been used widely for the Determination of primary antioxidant activity' that is, the free radical scavenging activities of pure antioxidant compounds, plant of Ocimumbasilicum oil. The assay is based on the reduction of DPPH radicals in ethanol which causes an absorbance drop at $517 \mathrm{~nm}$. In this study, the antioxidant activity was expressed as hundred percentage descriptive expression than assays that express antioxidant activity as the percentage decrease in absorbance. As such the results provide a direct comparison of the antioxidant activity with Trolox. The DPPH free radical scavenging activity ofplant extracts Basil oil showed the higher DPPH free radical scavenging activity in our study oil leave Ocimumbasilicum had the highest activity antioxidant (73\%) any result high than $50 \%$ calculate the $\mathrm{IC}_{50}$ value.

\subsection{2. $I C_{50}$ Calculation}

The IC50 (the concentration of test material, which possess $50 \%$ inhibition of free radicals) of all the extracts and their fractions was determined by monitoring the effect of different concentrations ranging from 500-62.2 / $\mathrm{ml}$. the IC50 of the extract and they were calculated using EZ-Fit Enzyme Kinetic program (perrella Scientific U.S.A).

\subsection{Cytotoxicity}

Cytotoxicity of extracts of leaves of ocimumbasilicum oil at different concentrations was evaluated by brine shrimp lethality.

\subsection{Brine Shrimp Lethality Test}

Results of cytotoxicity are presented in Tables 10.tested extract were non-toxic to brine shrimps at concentrations 10 and $100 \mathrm{ppm}$ and were toxic at concentration $1000 \mathrm{ppm}$ where $100 \%$ mortality was obtained. The $\mathrm{LD}_{50}$ value 186.3944 ppm indicating that all extract displayed moderate toxicity.

Table 4. Showed toxicity activity of ocimumbasilicum oil.

\begin{tabular}{llll}
\hline Sample & Concentration(ppm) & Dead & Survive \\
\hline \multirow{3}{*}{ Basil oil } & 10 & 0 & 10 \\
& 10 & 0 & 10 \\
& 10 & 0 & 10 \\
& 100 & 2 & 8 \\
& 100 & 4 & 6 \\
& 100 & 1 & 9 \\
& 1000 & 10 & 0 \\
& 1000 & 10 & 0 \\
\hline
\end{tabular}

Table 5. $L D_{50}$ value of brine shrimp lethality assay of stem extracts of ocimumbasilicum.

\begin{tabular}{lll}
\hline Extract & LD $_{\mathbf{5 0}}(\mathbf{p p m})$ & Remarks \\
\hline Ocimumbasilicum oil & 186.3944 & Moderate \\
\hline
\end{tabular}

\subsection{How to Use Formulas}

Developed a suitable amount of formulas on a specific area (arm and feet) and 25 centimeters by the time when start use of formulas until the disappearance of the pilot fuel formulas and smell of it we have acquired the results of which were these formulas can be used as pesticide repellent mosquitoes.
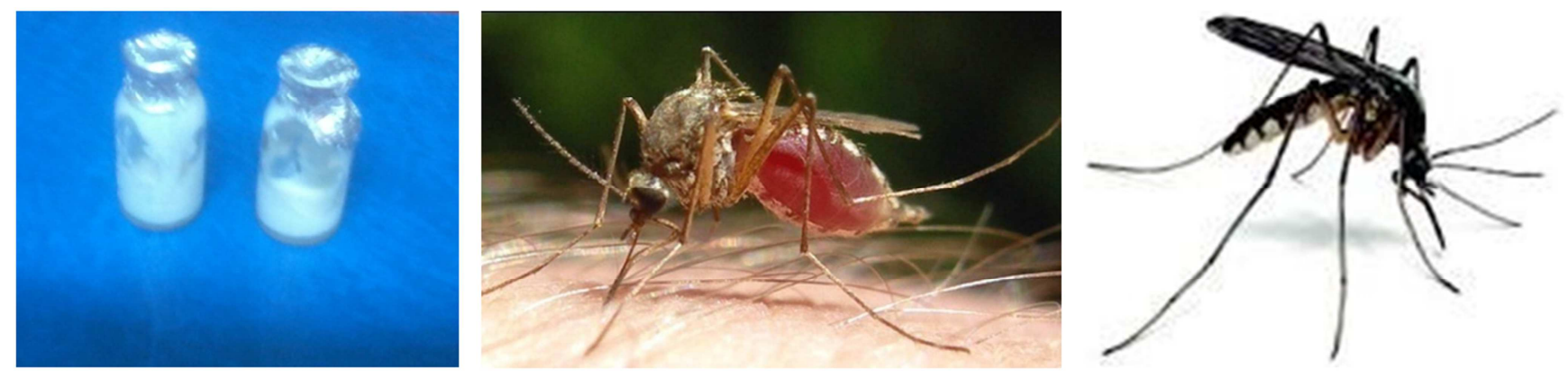

Figure 7. Mosquito and cream repellent mosquito product. 


\subsection{Statistical Analysis}

Academic level

Table 6. Showed the academic level.

\begin{tabular}{llllll}
\hline & Frequcy & Percet & Valid Percent & Cumulate Percent \\
\hline Valid & Primary & 1 & 4.3 & 4.3 & 17.4 \\
& Secondary & 4 & 17.4 & 43.5 & 21.7 \\
& Graduated & 10 & 43.5 & 34.8 & 65.2 \\
& Postgraate & 8 & 34.8 & 100.0 & 1000 \\
\hline
\end{tabular}

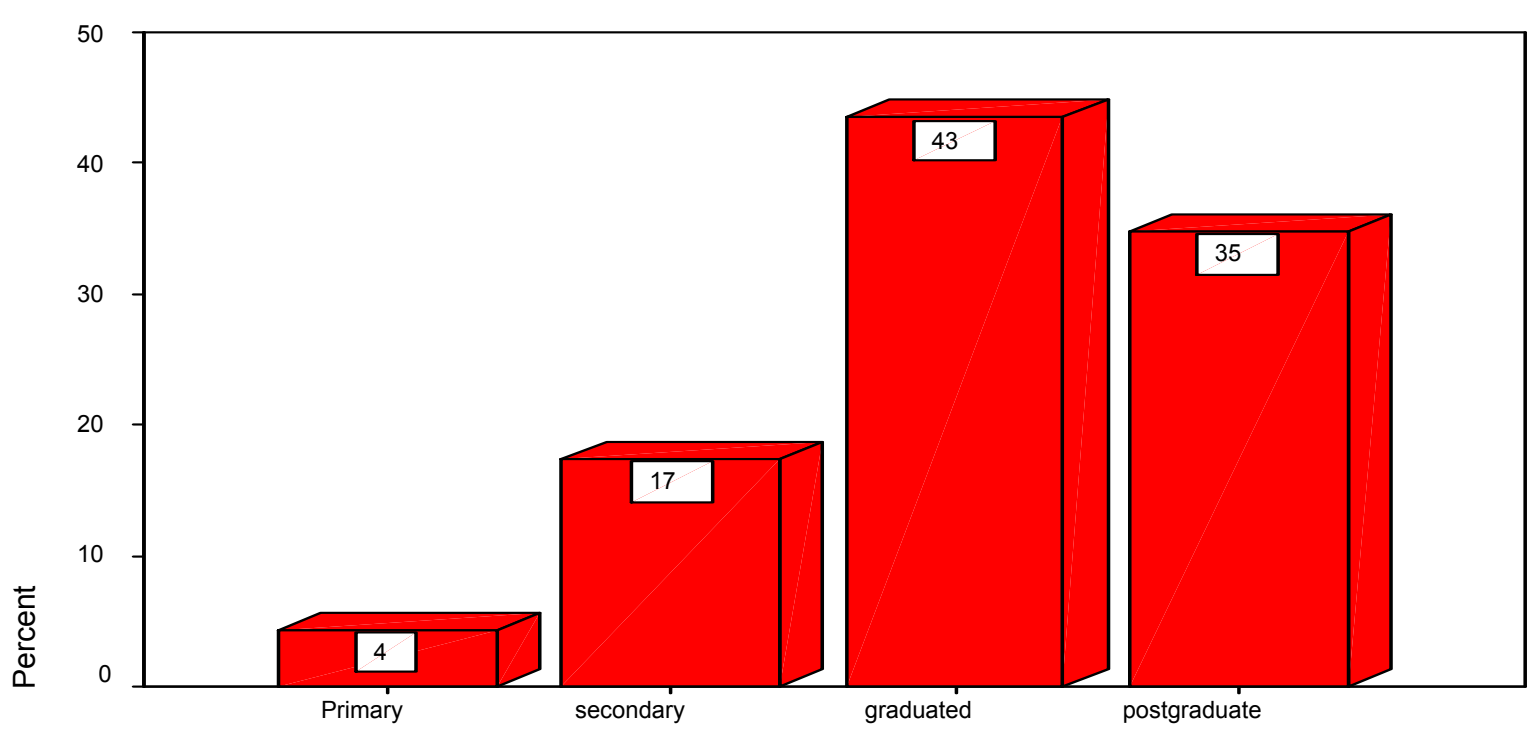

Figure 8. Academic level.

Level of household income

Table 7.Showed the level of household income.

\begin{tabular}{|c|c|c|c|c|c|}
\hline & & Frequency & Percent & Valid Percent & Cumulative Percent \\
\hline \multirow[t]{3}{*}{ Valid } & Midde & 20 & 87.0 & 87.0 & 87.0 \\
\hline & High & 3 & 13.0 & 13.0 & 100.0 \\
\hline & Total & 23 & 100.0 & 100.0 & \\
\hline
\end{tabular}

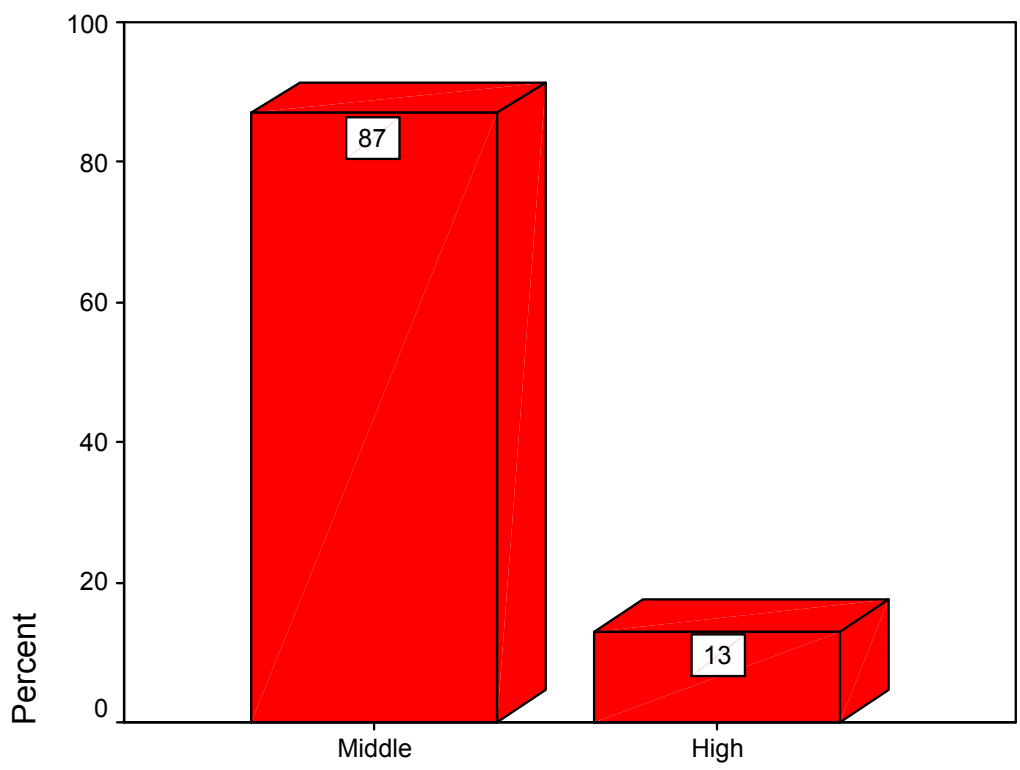

Figure 9. Showed the level of household income. 
Knowledge materials mosquito repellant

Table 8. Showed the knowledge materials mosquito repellant.

\begin{tabular}{llllll}
\hline & Frequncy & Percet & Valid Percent & Cumulatve Percent \\
\hline Valid & Extensie & 6 & 26.1 & 26.1 & 26.1 \\
& Middle & 9 & 39.1 & 39.1 & 65.2 \\
& Little & 7 & 30.4 & 30.4 & 95.7 \\
& Non & 1 & 4.3 & 4.3 & 100.0 \\
& Total & 23 & 100.0 & 100.0 & \\
\hline
\end{tabular}

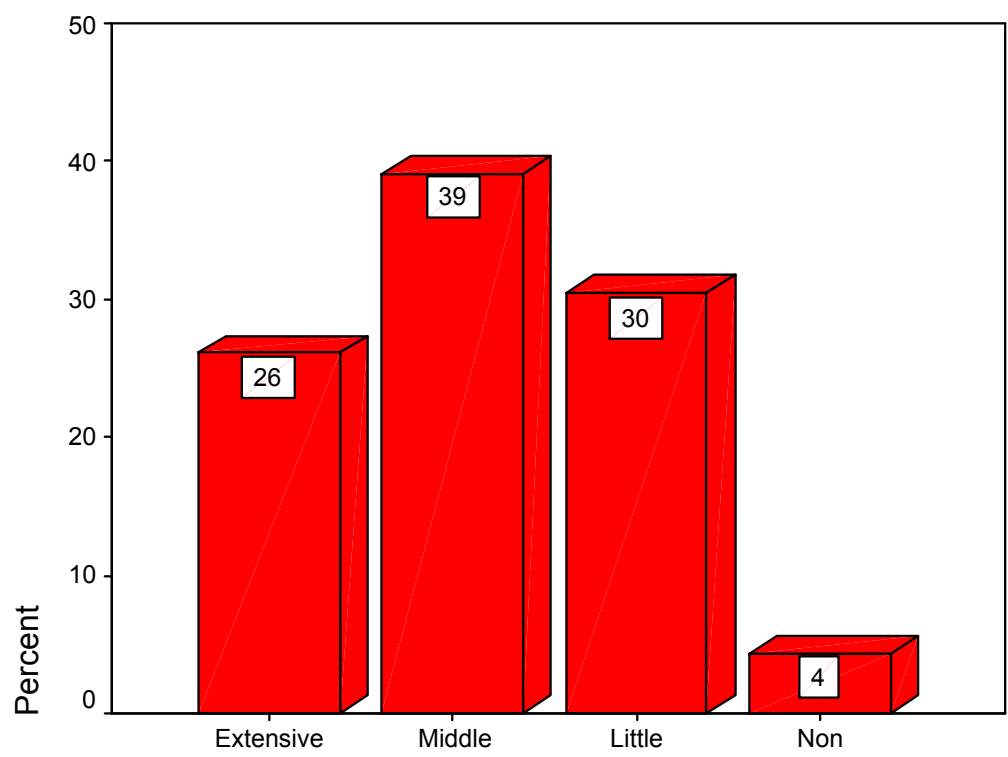

Figure 10. Knowledge materials mosquito repellant.

when you use the mosquito repellent creams Do you consider the preamble of the components

Table 9. Showed the When you use the mosquito repellent creams Do you consider the preamble of the components.

\begin{tabular}{llllll}
\hline & Frequency & Percent & Valid Percent & Cumulative Percent \\
\hline Valid & No & 9 & 39.1 & 39.1 & 39.1 \\
& Often & 9 & 39.1 & 79.1 & 21.7 \\
& Yes & 5 & 21.7 & 100.0 & 100.0 \\
\hline
\end{tabular}

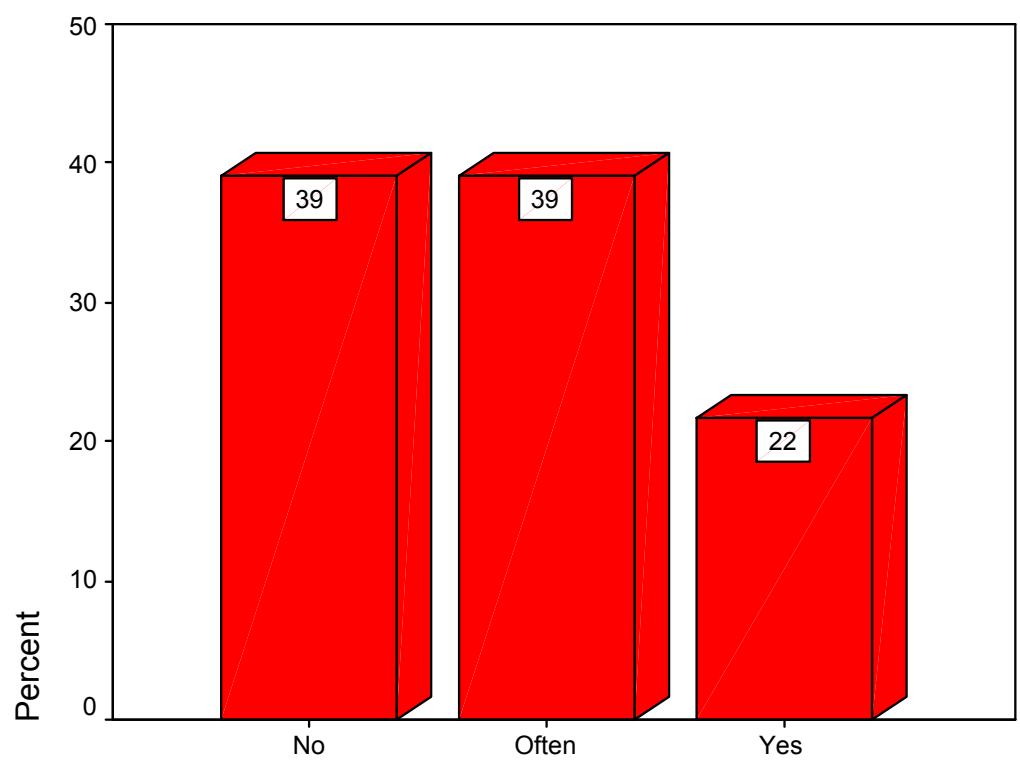

Figure 11. When you use the mosquito repellent creams do you consider the preamble of the components. 
Whichever you prefer creams repellents or pesticides mosquito of a chemical

Table 10. Showed whichever you prefer creams repellents or pesticides mosquito of a chemical.

\begin{tabular}{llllll}
\hline & & Frequency & Percent & Valid Percent & Cumulative Percent \\
\hline Valid & Natural & 22 & 95.7 & 95.7 & 95.7 \\
& Chemically processed & 1 & 4.3 & 4.3 & 100.0 \\
& Total & 23 & 100.0 & 100.0 & \\
\hline
\end{tabular}

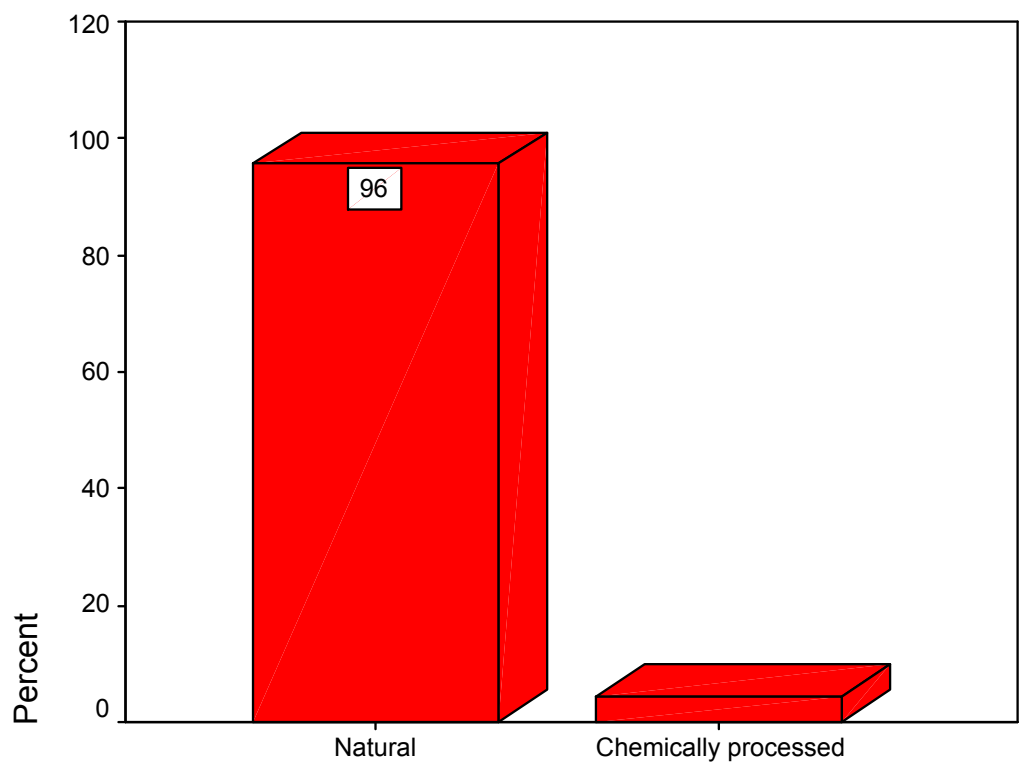

Figure 12. Whichever you prefer creams repellents or pesticides mosquito of a chemical.

Are there any side effects when using the cream?

Table 11. Showed the Are there any side effects when using the cream.

\begin{tabular}{llllll}
\hline & & Frequency & Percent & Valid Percent & Cumulative Percent \\
\hline \multirow{3}{*}{ Valid } & Yes & 1 & 4.3 & 4.3 & 4.3 \\
& No & 22 & 95.7 & 95.7 & 100.0 \\
& Total & 23 & 100.0 & 100.0 & \\
\hline
\end{tabular}

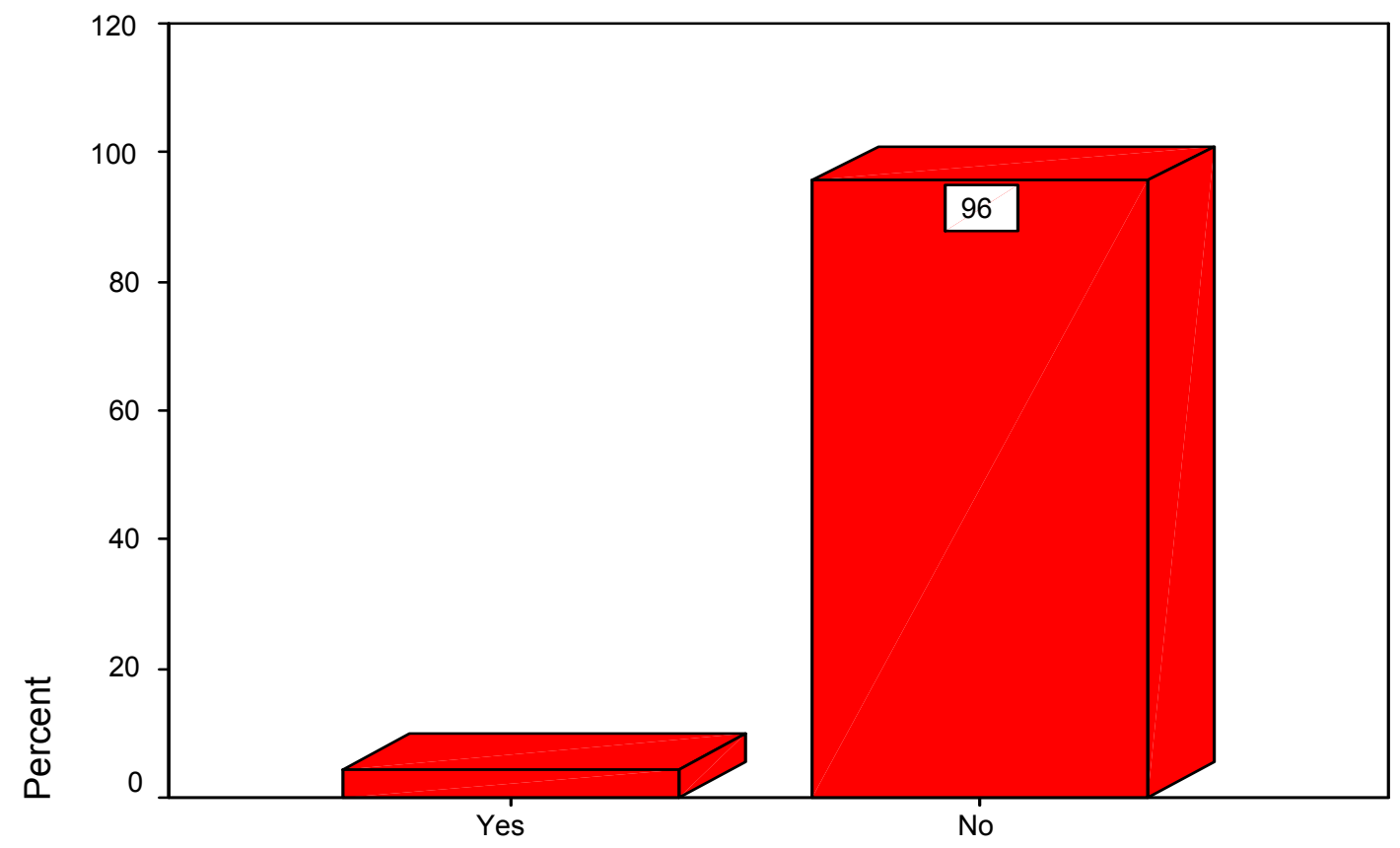

Figure 13. Are there any side effects when using the cream. 
Table 12. Showed the Time.

\begin{tabular}{lllllll}
\hline Groups & N & Mean & Std. Deviation & Std. Error Mean( $( \pm)$ & T-Test & d-f \\
\hline Control & 23 & 3.0217 & 1.21989 & .25437 & -4.174 & 44 \\
Test & 23 & 5.0435 & 1.97664 & .41216 & $0.00 *$ \\
\hline
\end{tabular}

*Significant different at the 0.05 level.

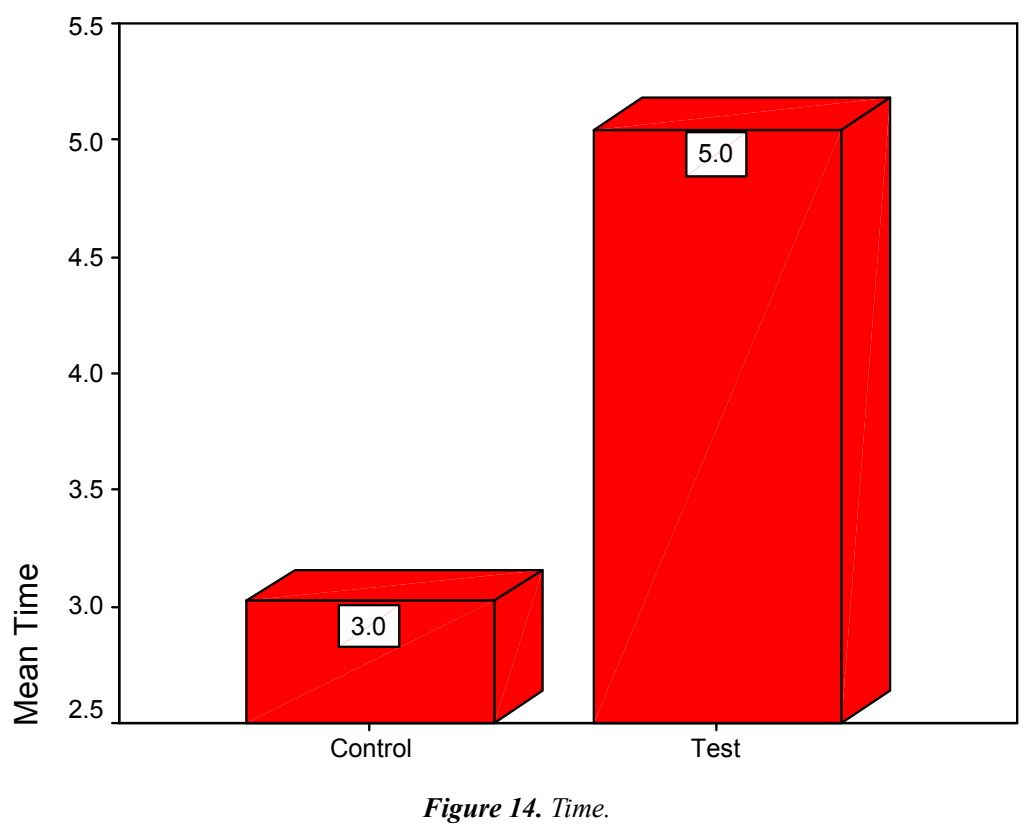

This study was prepare mosquito repellent cream from ocimumbasilicum oil Moreover, mosquito repellents provided in the market have a short life of action ( $3 \mathrm{hrs}$ ) so this study was conducted to prolong the life of ocimumbasilicum oil cream action as a mosquito repellent for (5 hours)according to statistical analysis above.

\section{Conclusion}

The emulsion formulation containing basil oil, dependent repellent of mosquito for long time.

Emulsion may be a good alternative to other pesticides for the control of vector-borne diseases.

Very important phytochemicals were obtained in Ocimum basilicum. These are biologically active substances that perform the function of preventing, healing and provision of antioxidant and antimicrobial properties to the body.

They are essential component of human nutrition. These findings justify the ethno-medicinal use of the plant.

\section{Recommendation}

- The principal raw material required by the plant is ocimumbasilicum which is locally available we therefore Recommend manufactures cream repellent mosquito plant locally to help fight malaria.

- It is therefore recommended that a quantitative phytochemical analysis of the plant should be conducted. Water solvent may be used in the extraction to provide full data on the components. This would maximize information on its nutritional and medicinal uses.

- I recommend that had further studies to benefit from the plant basil in pest control and take advantage of the cream formula repellent mosquito bites in some other insects

\section{References}

[1] Makhaik M., Naik SN., Tewary DK. Evaluation of antimosquito properties of essential oils. J Scilnd Res 2005; 64: 129-133.

[2] Journal of Medicinal Plants Research Vol. 7(11), pp. 653-660, 17 March, 2013 Available online at http://www.academic journals.org/JMPR.

[3] CHEM 333L Organic Chemistry Laboratory http://infohost.nmt.edu/ jaltig/ Steam Distill. Date added: November 12, 2011 Revision 2.1.

[4] A.O.A.C. 1984. Official methods of analysis. $15^{\text {th }}$ Ed. Association of official analytical chemists. Washington, DC. USA.

[5] Barrow, G. I., and Feltham, R.K.A. (1993). Cowan and Steels Manual for the Identification of Medical Bacteria. 3rd edition. Cambridge University press, Cambridge, U.K.

[6] Miles, A. A. and Misra, S. S. (1938). Estimation of bacterial power of blood.Journal of Hygiene38: 732-735.

[7] Onkar, D., Dhigra, J. James, B. (1995). Basic plant pathology method 287-305. 
141 Amar Osman Ali Salih et al: Bioassay of Herbal Mosquito Repellent Formulated from the Essential Oil of Ocimum Basilicum

[8] Shimada k, Fujjkawa k,yahara k, Nakamura T.Antioxiadative properties of xanthan on the Antioxidation of soybean oil in cyclodextrain emulsion. JAgric food chem. 1992,40:945-8.

[9] Pisutthanan, S., Plianbangchang, P., Pisutthanan, N., Ruanruay, S and Muanrit, O. (2004). Brine shrimp lethality activity of Thai medicinal plants in the family Meliaceae. J. Naresuan University 12: 13-18.
[10] Parra, A.L., Yhebra, R.S., Sardinas, I, G. and Buela, L.I., (2001). Comparative study of the assay of Artemiasalina and the estimate of the 12.medium lethal dose $\left(\mathrm{LD}_{50}\right.$ value) in mice, to determine oral acute toxicity of plant extracts. Phytomedicine 8(5): 395-400. 